

\title{
Deformation Mechanism of Cement Paste and Hydrates under High Stress
}

\author{
Yuya Sakai $^{1^{*}}$ and Shin-ichi Uehara ${ }^{2}$
}

\begin{abstract}
Hardened cement paste (HCP) and compacts made of hydrates were analysed to understand the deformation mechanism of hardened concrete. A normal creep test and a creep test with stepwise increasing load were performed on HCP, and the results indicated that the deformation of HCP is governed by dislocation creep. The stepwise creep test was performed on the compacts of calcium hydroxide, synthesized ettringite, and calcium silicate hydrate $(\mathrm{C}-\mathrm{S}-\mathrm{H})$, and crushed HCP at a confining pressure of $50 \mathrm{MPa}$. The hydrates, except for C-S-H, demonstrated similar behaviour, and the slope of the strain rate-differential stress curve was approximately three. According to a common classification, this slope indicates the deformation governed by dislocation creep. The synthesized C-S-H showed a higher strain rate compared to the other hydrates, and the slope in this case was negative or approximately zero. Therefore, we inferred that the deformation mechanism of C-S-H is different from those of the other hydrates and that C-S-H is not dominant when HCP deforms under high confining pressure. However, C-S-H occupies the largest volume in HCP. We justified this contradiction by assuming that C-S-H is squeezed out rapidly in the deformation; the structure then formed is composed of hydrates other than $\mathrm{C}-\mathrm{S}-\mathrm{H}$, and the deformation of this structure is governed by dislocation creep.
\end{abstract}

\section{Introduction}

The deformation and failure mechanisms of concrete are important because these mechanisms are related to the strength and long-term behaviour of concrete structures. Many researchers have studied the macroscopic phenomena and deformation and failure mechanisms of concrete subjected to compressive stress and have arrived at certain unanimous results: micro-cracks are initiated at the interface of cement paste and aggregate, these micro-cracks begin to grow under certain stress, and finally, the cracks propagate to failure (Akçaoğlu et al. 2004; Hsu et al. 1963; Mihashi et al. 1979; Shah and Chandra 1968; Yamaguchi and Chen 1991). At a sustained lower stress level, concrete suffers creep deformation, and the mechanism of the creep deformation is different from that of general failure mentioned above. Many mechanisms have been suggested for creep deformation including mechanical damage (Pickett 1942), but C-S-H is generally believed to play an important role in the deformation. Specifically, water squeezing from $\mathrm{C}-\mathrm{S}-\mathrm{H}$ and slip in C-S-H are regarded as the main reasons for creep deformation (Ali and Kesler 1964; Powers 1968). When the magnitude of a sustained load is increased, the specimen fails even if the corresponding stress is lower than the compressive strength. This threshold value of the stress to failure is called the creep

\footnotetext{
${ }^{1}$ Assistant Professor, Institute of Industrial Science, The University of Tokyo, Ce-505, 4-6-1 Komaba, Meguro, Tokyo 153-8505, Japan. *Corresponding author,

E-mail: ysakai@iis.u-tokyo.ac.jp

${ }^{2}$ Associate Professor, Department of Environmental Science, Toho University, 2-2-1 Miyama, Funabashi, Chiba 274-8510, Japan.
}

limit, and this limit usually ranges from $70 \%$ to $80 \%$ of the compressive strength (Ngab et al. 1981; Rusch 1961; Smadi et al. 1982). This behaviour of concrete changes when it is subjected to a confining pressure. Concrete can deform extensively under high confining pressure without stress drop, though such a situation causes macroscopic damage (Gabet et al. 2008; Malecot et al. 2010; Poinard et al. 2010; Sfer et al. 2002). On the other hand, hardened cement paste (HCP) can undergo large deformation without damage under confining pressure (Sakai et al. 2016; Sakai and Kishi 2017). In this case, HCP does not fracture; therefore, the mechanism of the large deformation clearly involves more than just the initiation and development of cracks. In addition, the strain rate during the deformation is larger than that in normal creep deformation; therefore, the deformation in HCP might be a result of an unknown mechanism. Concrete suffers high confining pressure not only when it is located in deep sea water and deep underground regions but also when a concrete member has a high reinforcement rate or a large cross section. Therefore, the cement paste in such concrete installations may be deformed by this unknown mechanism, and it is important to understand the mechanism to decisively control the deformation and failure of concrete.

Considering that rocks are generally subjected to high pressure, Sakai et al. (2016) applied a method used in rock mechanics to understand the deformation mechanism of HCP. In this method, the deformation mechanism is classified by the slope of the differential stress-strain rate relationship. This method is widely used for not only rocks but also metals, ice, metallic glass, etc. (Bürgmann and Dresen 2008; Goldsby and Kohlstedt 1995; Mei and Kohlstedt 2000; Sato et al. 2005; Zheng et al. 1991). Sakai and Kishi (2017) measured the strain rate of HCP 
Table 1 Chemical composition of cement.

\begin{tabular}{|c|c|c|c|c|c|c|c|c|c|}
\hline \multicolumn{10}{|c|}{ Chemical property (\%) } \\
\hline Ig. Loss & Insol. & $\mathrm{SiO}_{2}$ & $\mathrm{Al}_{2} \mathrm{O}_{3}$ & $\mathrm{Fe}_{2} \mathrm{O}_{3}$ & $\mathrm{CaO}$ & $\mathrm{MgO}$ & $\mathrm{SO}_{3}$ & $\mathrm{Na}_{2} \mathrm{O}$ & $\mathrm{K}_{2} \mathrm{O}$ \\
\hline 2.64 & 0.06 & 20.27 & 5.3 & 2.95 & 64.82 & 0.95 & 1.74 & 0.28 & 0.45 \\
\hline
\end{tabular}

by performing a creep test with stepwise increasing load and reported that the slope of the differential stress-strain rate relationship was approximately six regardless of the confining pressure and the water content. The slope of six indicates that the deformation is governed by dislocation creep (Bürgmann and Dresen 2008). Here, dislocation occurs in the form of a linear defect in a crystal material, and the dislocation creep is the deformation caused by the movement of the dislocation (Mei and Kohlstedt 2000; Zheng et al. 1991). However, Sakai and Kishi (2017) could not conclude that the deformation of HCP under high confining pressure is governed by dislocation creep because a large volume of cement paste is occupied by $\mathrm{C}-\mathrm{S}-\mathrm{H}$, which is regarded to be a gel material, and dislocation cannot be defined in a non-crystalline material (Schuh et al. 2007). Sakai and Kishi (2017) indicated the possibilities that C-S-H deforms because of a mechanism similar to dislocation creep or that the hydrates other than C-S-H are dominant in the deformation of $\mathrm{HCP}$, but these possibilities were not conclusively demonstrated. In addition, in the stepwise creep test, stepwise increasing loads are applied to a specimen, and therefore, hysterical effects can be included in the measured results; however, it is not certain whether the same results can be obtained in a normal creep test.

In this research, first, a normal creep test was performed on HCP to confirm that the obtained results were similar to those obtained in a stepwise creep test. Then, to gain a more in-depth understanding about the deformation mechanism of HCP under confining pressure, the strain rates of not only $\mathrm{HCP}$ but also synthesised hydrates were measured, and the deformation mechanism was discussed based on the relationship between the strain rate and the differential stress.

\section{Experimental}

\subsection{Preparation of specimens}

\section{(1) Cement paste}

In this research, cement paste (water-to-cement ratio: 0.4 ) made from ordinary Portland cement was used. The properties of the cement are presented in Tables $\mathbf{1}$ and $\mathbf{2}$. The HCPs used for the normal creep test were cylinders (diameter: $50 \mathrm{~mm}$, height: $100 \mathrm{~mm}$ ). These cylinders were demoulded $24 \mathrm{~h}$ after casting and cured under water. At the age of 28 days, these cylinders were removed from the water and strain gauges were attached on them after removing the moisture from the surface. These saturated cylinders were sealed in plastic bags, and a creep test was performed on them. In the stepwise creep test, two types of HCP cylinder specimens (diameter: $20 \mathrm{~mm}$, height: 40 $\mathrm{mm}$ ) were used. The first type of specimens was prepared
Table 2 Physical properties of cement.

\begin{tabular}{|c|c|}
\hline Density & Specific surface area \\
\hline $\mathrm{g} / \mathrm{cm}^{3}$ & $\mathrm{~cm}^{2} / \mathrm{g}$ \\
\hline 3.14 & 3460 \\
\hline
\end{tabular}

by coring; a prism of $10 \times 10 \times 40 \mathrm{~cm}$ was cast, demoulded $24 \mathrm{~h}$ later, and cured under water. The specimens were cored at the age of 28 days and kept in a sealed container until the test at the age of 2 years. The other type of specimens was prepared by compaction after crushing in order to allow comparison with the compacts of hydrates, as explained later. Cement paste was cast into a plastic bag and sealed for 2 days. Then, the HCP was crushed using a jaw crusher until the maximum size of the fragments became smaller than 1 $\mathrm{cm}$. The crushed HCP was immersed in water until the age of 28 days and dried at $40^{\circ} \mathrm{C}$ and a relative humidity (RH) of $10 \%$ for 3 days. The crushed HCP was crushed again using a blender until the maximum particle size became less than $200 \mu \mathrm{m}$, and the obtained powder was cured in a sealed container. At the age of 3 months, the prepared powder was compressed from the top and the bottom at a pressure of $100 \mathrm{MPa}$ to prepare compacts that were $40 \mathrm{~mm}$ in height and $20 \mathrm{~mm}$ in diameter. The compaction was also carried out on wet powders prepared by mixing the dry powders and water, whose weight corresponded to $15 \%$ of the powder. After the wet compaction, the compacts were dried at $40^{\circ} \mathrm{C}$ and $10 \%$ $\mathrm{RH}$ for 3 days, and the stepwise creep test was performed. The entire process mentioned above was carried out in a room maintained at $20^{\circ} \mathrm{C}$ unless otherwise noted.

\section{(2) Hydrates}

The calcium hydroxide used in this study was a commercially available special grade reagent having a purity of $96 \%$. Ettringite was synthesised by following the method proposed by the Japan Cement Association (2016); calcium hydroxide and hydrated aluminium sulphate were mixed at a molar ratio of $6: 1$, and distilled water was added to the mixture. The mixture was then heated to $60^{\circ} \mathrm{C}$ and stirred for 3 days. Then, the mixture was kept at $20^{\circ} \mathrm{C}$ for 1 week and then filtered by rinsing with distilled water, following which it was dried at $40^{\circ} \mathrm{C}$ and $10 \% \mathrm{RH}$ for $48 \mathrm{~h}$. C-S-H was synthesised by following the procedure of Nakamura et al. (1999). Tetraethyl orthosilicate, ethanol, distilled water, and hydrochloric acid were mixed at a molar ratio of $1: 4: 2: 0.02$. The saturated solution of calcium hydrate was then added so that the molar ratio of $\mathrm{CaO}$ to $\mathrm{SiO}_{2}$ became 1.1, and the mixture was stirred for 2 days in nitrogen atmosphere and dried at $40^{\circ} \mathrm{C}$ and $10 \% \mathrm{RH}$ for $48 \mathrm{~h}$. The results of the X-ray diffraction analysis of the synthesised ettringite and $\mathrm{C}-\mathrm{S}-\mathrm{H}$ are shown in Fig. 1, and the profiles are 
Table 3 Porosity of the samples (Dry/Wet in the table indicates dry/wet compaction).

\begin{tabular}{|c|c|c|c|c|c|c|c|c|}
\hline \multicolumn{10}{|c|}{ Porosity (\%) } \\
\hline \multirow{2}{*}{ Non-crushed HCP } & \multicolumn{2}{|c|}{ Crushed HCP } & \multicolumn{2}{c|}{ Calcium hydroxide } & \multicolumn{2}{c|}{ Synthesized ettringite } & \multicolumn{2}{c|}{ Synthesized C-S-H } \\
\cline { 2 - 10 } & Dry & Wet & Dry & Wet & Dry & Wet & Dry & Wet \\
\hline 14.2 & 27.4 & 26.9 & 32.8 & 20.5 & 41.0 & 23.3 & 51.4 & 53.3 \\
\hline
\end{tabular}

similar to those found in the literature; therefore, we concluded that the synthesis was successful. These dry hydrates were milled until the maximum particle size of the powder became smaller than $200 \mu \mathrm{m}$, and the compacts were prepared by dry and wet compaction, as explained in the previous sub-section. The porosity of the hydrates and the HCPs before the triaxial test was measured using a pycnometer (Ultrapyc, Quantachrome, Florida, USA). He gas was used as a measurement gas. The results are presented in Table 3.

\subsection{Normal creep test under high stress}

In the stepwise creep test, the deformation at each loading step can possibly affect the deformation in the following steps. To confirm this, a normal creep test was performed on HCP with a diameter of $50 \mathrm{~mm}$ and a height of $100 \mathrm{~mm}$ using a universal testing machine. Before the creep test, the compressive strength of three specimens was measured at a loading rate of $0.6 \mathrm{MPa} / \mathrm{s}$ to obtain the average compressive strength. Then, a sustained load corresponding to $70-90 \%$ of the obtained compressive strength was applied to seven specimens to perform the creep test. In the creep test, the load was increased at a rate of $0.6 \mathrm{MPa} / \mathrm{s}$, and the load was sus-

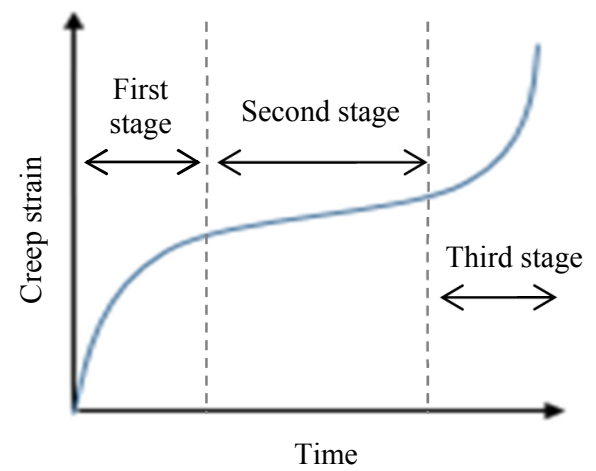

Fig. 2 Classification of creep deformation process.

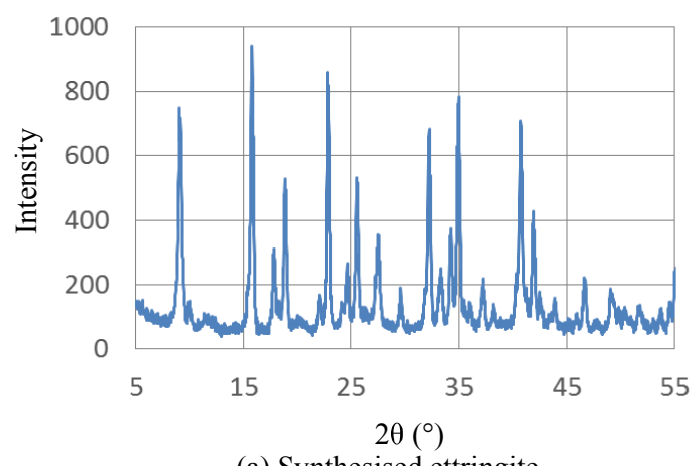

(a) Synthesised ettringite tained at certain stresses. The strain of the specimens was measured using strain gauges (gauge length: $60 \mathrm{~mm}$ ) placed on the specimen surfaces. The strain rate was calculated from the slope of the obtained strain-time relationship in the steady state. Here, the steady state corresponds to the second stage if the creep deformation is divided into three stages (Fig. 2). In the second stage, the slope of the curve becomes constant. Ideally, creep strain increases suddenly in the third stage, but this stage is not apparent in brittle materials.

\subsection{Stepwise creep test}

(1) Apparatus and sample setup

An intra-vessel deformation and fluid flow apparatus was used for the test involving confining pressure. The specimen was placed between two stainless-steel spacers and fixed using heat-shrinking tubes made of a polyolefin. These spacers have penetrated holes, and the pore pressure can be adjusted using these holes. In this study, the pore pressure in the specimens was maintained at the atmospheric pressure. Then, two stainless-steel pistons were connected to the specimen and the spacers, and they were fixed using heat-shrinking tubes and wires. The ends of the heat-shrinking tubes were sealed using instant glue. The prepared assembly was connected to a stainless-steel base, which was connected to a load cell, and inserted into the pressure vessel. Confining pressure was applied by filling machine oil in the vessel, and load was applied by moving the actuator located at the bottom of the vessel in the upward direction. The sample assembly and the schematic of the apparatus are shown in Fig. 3. The stress applied to the specimen was calculated by dividing the measured load by the cross-sectional area of the specimen. The calculated stress corresponded to the differential stress because the load cell was in the pressure vessel and the measured load did not include the effect of the confining pressure. In this study, the dif-

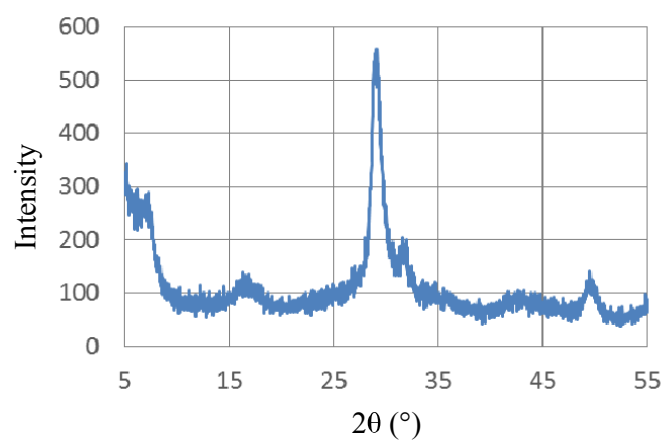

(b) Synthesised C-S-H

Fig. 1 X-ray diffraction patterns of synthesised hydrates. 
ferential stress was considered to be the difference between the axial stress and the confining pressure. The strain was calculated by dividing the displacement measured using the displacement gauges (resolution of 1 $\mu \mathrm{m})$ by the initial length of the specimen. The measured displacement was corrected by considering the deformation of the apparatus, which was calculated using the stiffness of the apparatus ( $487 \mathrm{kN} / \mathrm{mm})$. Figure 4 shows the path of the confining pressure and the loading. First, hydrostatic pressure was applied to the specimen, and then, the axial stress was increased. The applied hydrostatic pressure was $50 \mathrm{MPa}$ in all the cases because at a certain confining pressure, the ductility of the samples increases and the measurement of the strain rate becomes easier. After the test, the axial stress was reduced to zero, and then, the confining pressure was relieved. The measurement interval of the load, strain, and confining pressure was $1 \mathrm{~s}$.

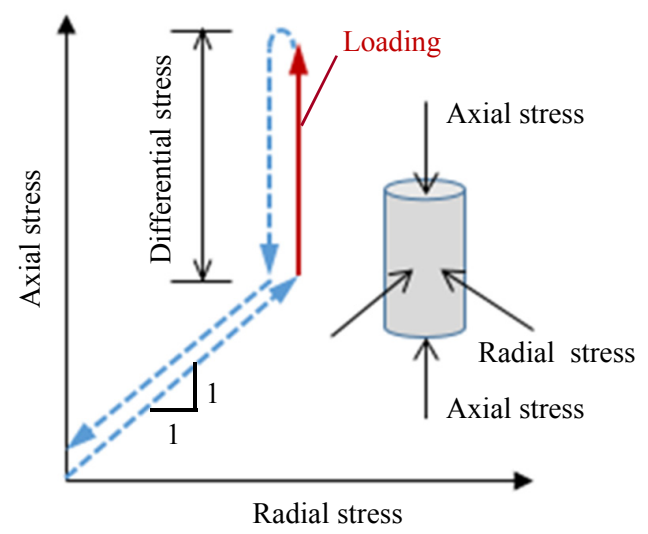

Fig. 4 Stress path used for sample.

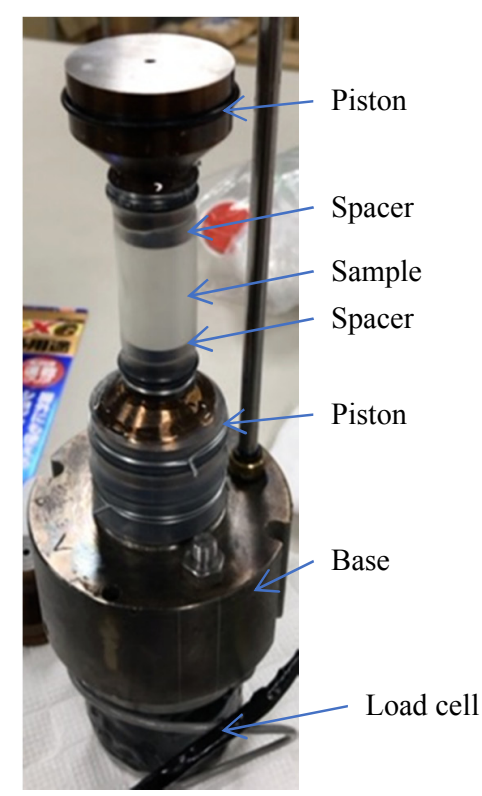

(a) Sample assembly

\section{(2) Apparatus and sample setup}

To obtain the relationship between the strain rate and the differential stress, a creep test with stepwise increasing load was performed. The load was increased with a displacement control of $0.06 \mathrm{~mm} / \mathrm{min}$ until the load reached a certain value, and then, the load was sustained. Next, the load was increased when the strain increment reached $0.1 \%$ or the duration time of the sustained load reached 20 min. Brantut et al. (2016) proposed that the strain at one step should be less than $0.02 \%$; however, in this study, a value of $0.1 \%$ was employed because the specimen height was $40 \mathrm{~mm}$, and a strain of $0.02 \%$ corresponded to a displacement of $8 \mu \mathrm{m}$, which was not sufficiently large to be measured by a displacement gauge with a resolution of $1 \mu \mathrm{m}$. Following the study of Zhang and Spiers (2005), the corresponding slope was calculated to obtain the strain rate when the strain increment after reaching a certain load value reached $0.04 \%$. The calculated slope barely depended on the strain where the strain rate was calculated.

\section{Results and discussions}

\subsection{Normal creep test under high stress}

The compressive test at a constant loading rate was performed on HCPs prior to the normal creep test, and the obtained average strength was $45.3 \mathrm{MPa}$. The normal creep test was then performed by applying stresses that corresponded to $70-90 \%$ of the obtained average strength. Some of the obtained strain-time relationships are shown in Fig. 5. The strain includes the elastic and creep strains. The strain rate was calculated from the slope by applying the method of least squares to the range between the point where the decrease in slope stagnated and the end of the measurement, or just before

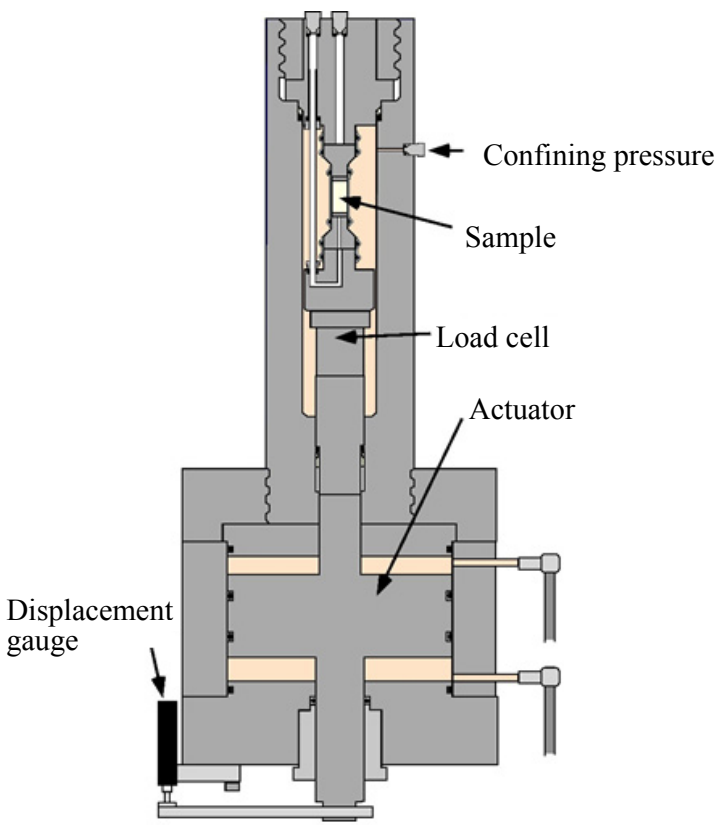

(b) Schematic diagram of tri-axial testing apparatus

Fig. 3 Testing apparatus. 
the sudden decrease in strain owing to the removal of the strain gage. The strain increase seen in the third stage in Fig. 2 is not shown in Fig. 5 because the strain gauges on the specimen surface were exfoliated as the fracture progressed, so it was assumed that the curve reached the steady state before the strain gauges came off. The specimen subjected to the stress corresponding to $70 \%$ of the strength did not fail, so it was assumed that the curve reached the steady state during the last part of the test. The relationship between the calculated strain rate and the differential stress is shown in Fig. 6, with the lines indicating the slopes of 3,6 , and 10 . The trend of the plots is close to the line with the slope of 10 . When the deformation mechanism is classified based on the slope, a slope of one indicates a creep governed by diffusion and a slope larger than one indicates a creep governed by

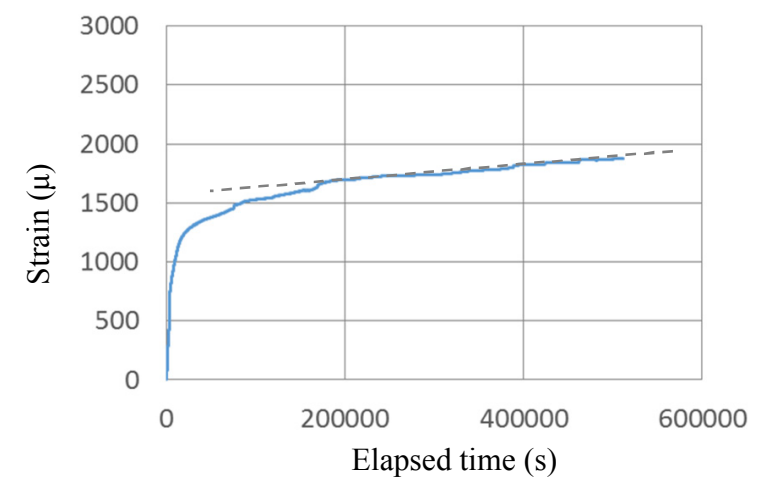

(a) Load corresponding to $70 \%$ of maximum stress

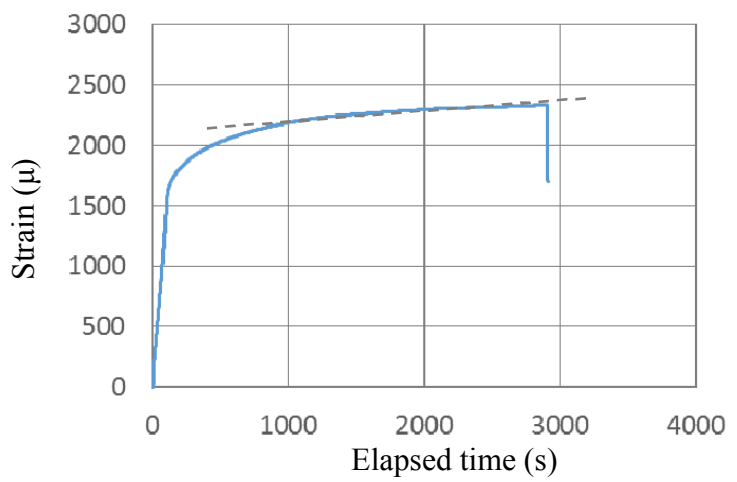

(b) Load corresponding to $80 \%$ of maximum stress

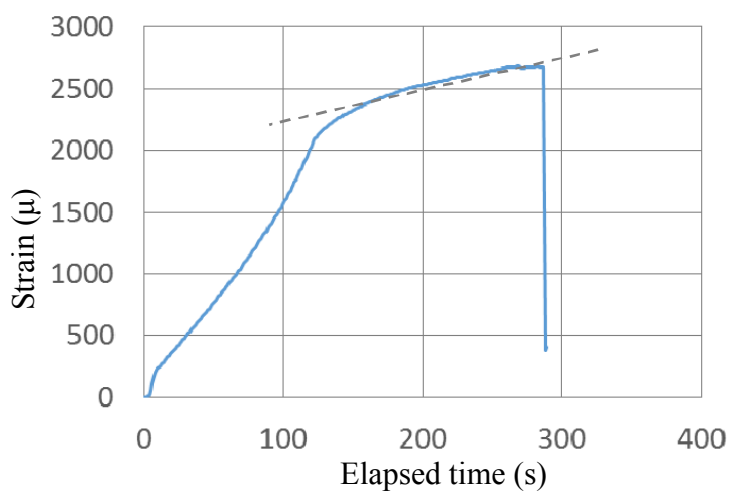

(c) Load corresponding to $90 \%$ of maximum stress

Fig. 5 Strain-time relationship in normal creep test. dislocation (Mei and Kohlstedt 2000). In the present study, the obtained slope is 10 , which is slightly large for dislocation creep; however, it is not unusual for the slope to be 10 or larger in rock and metal depending on the material or experimental conditions (Ferkel and Mordike 2001; Kainer 2006; Leo 2017; Okubo et al. 2013; Rathbun et al. 2008; Sugino et al. 2012).

\subsection{Stepwise creep test}

The stepwise creep test was performed at a confining pressure of $50 \mathrm{MPa}$. The obtained relationships between the differential stress and axial strain of the samples prepared by dry and wet compaction are shown in Figs. 7 and $\mathbf{8}$, respectively. The results for the uncrushed HCP are shown in both the figures as a reference, and it has the highest stiffness among all the specimens. As shown in Fig. 7, all the dry-compacted samples exhibit similar behaviour up to $1 \%$ strain and similar slope after the deflection, though the deflection points of the curves are different. In Fig. 8, calcium hydroxide and crushed HCP exhibit almost the same behaviour and the synthesised $\mathrm{C}-\mathrm{S}-\mathrm{H}$ has the lowest stiffness. The compacts prepared by dry compaction exhibit lower stiffness than those prepared by wet compaction except for C-S-H that showed higher stiffness in the dry compacted sample.

The relationships between the strain increment and the elapsed time after reaching each set stress in the compacts prepared by dry and wet compaction are shown in Figs. 9 and 10, respectively. The values in the legends of the figures represent the applied differential stress. The slope of the dry-compacted samples is large and change only slightly with stress when the stress level is high. The wet-compacted C-S-H shows the similar tendency though the other wet compacted samples showed gradual increase of the slope with stress level.

Figures 11 and 12 show the relationships between the differential stress and the calculated strain rate for the dry- and wet-compacted samples at a strain of $0.04 \%$. The calculated slope barely depended on the strain where the strain rate was calculated. The data for the uncrushed HCP are also shown in both figures as a reference and the slopes are approximately six. The slope obtained in the normal creep test (Fig. 6) is ten, larger than these

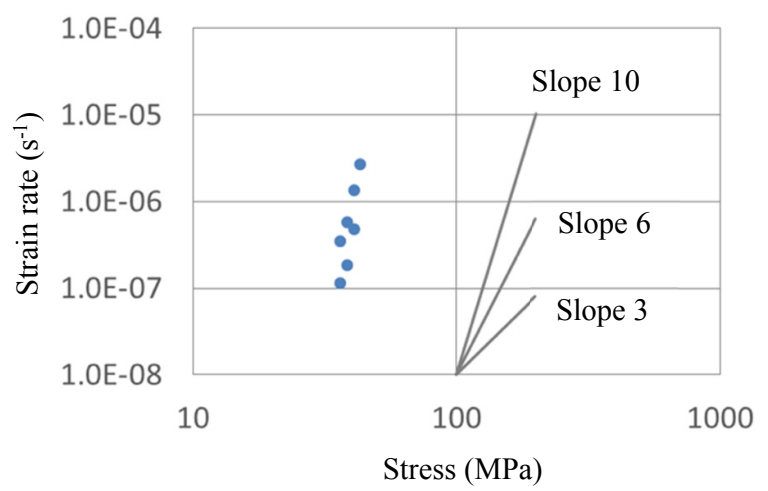

Fig. 6 Strain rate-differential stress relationship of non-crushed cement in normal creep test. 
probably because the pore is compressed at each loading step in the stepwise creep test and when the load is increased, the specimen is compacted and exhibits a smaller strain rate, i.e., a smaller slope. According to the general classification, the results of both the tests indicate

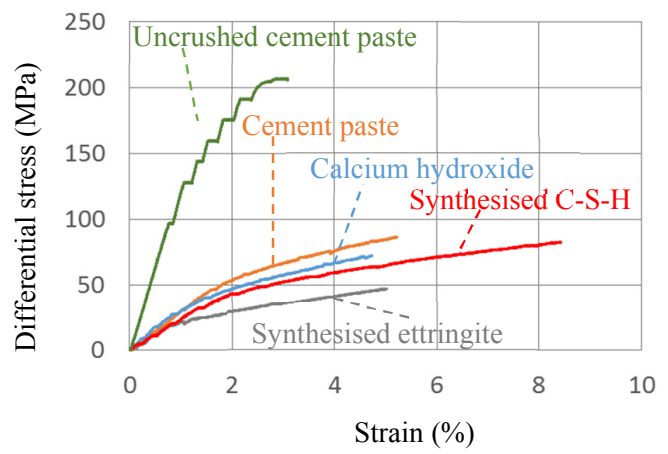

Fig. 7 Differential stress-strain relationship of dry-compacted samples in stepwise creep test.

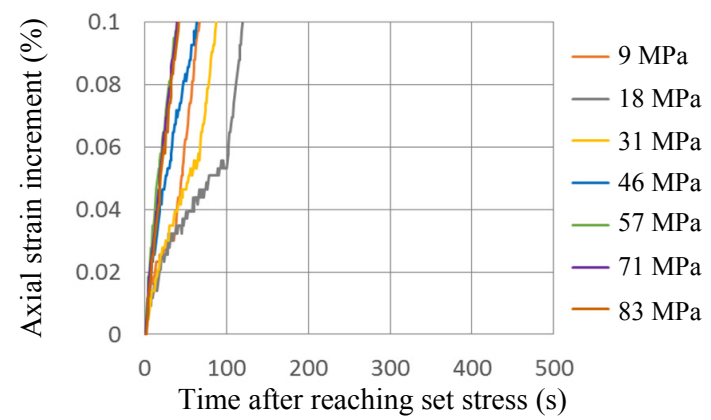

(a) Cement paste

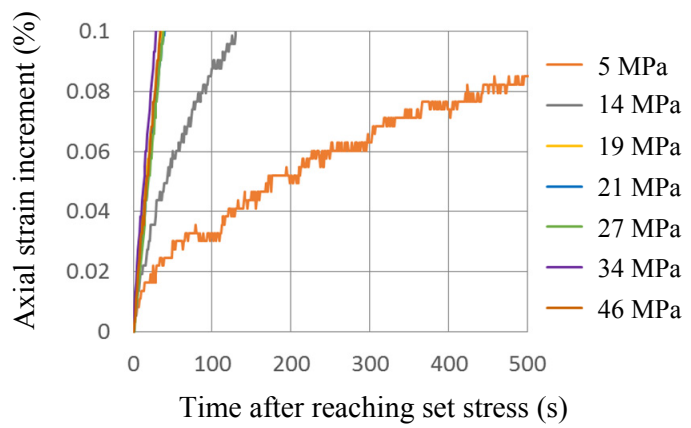

(c) Synthesised ettringite that the deformation mechanism of HCP is classified as dislocation creep.

In Fig. 11, all the hydrates exhibit similar trends: the slopes of the plots are approximately one up to a differential stress of $30 \mathrm{MPa}$ and then become almost zero.

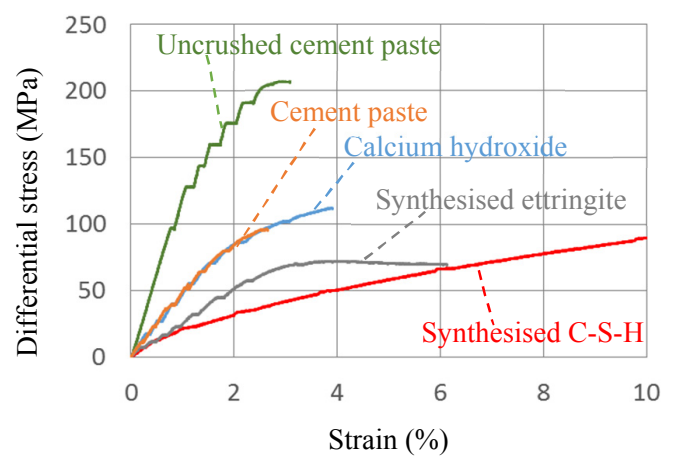

Fig. 8 Differential stress-strain relationship of wet-compacted samples in stepwise creep test.

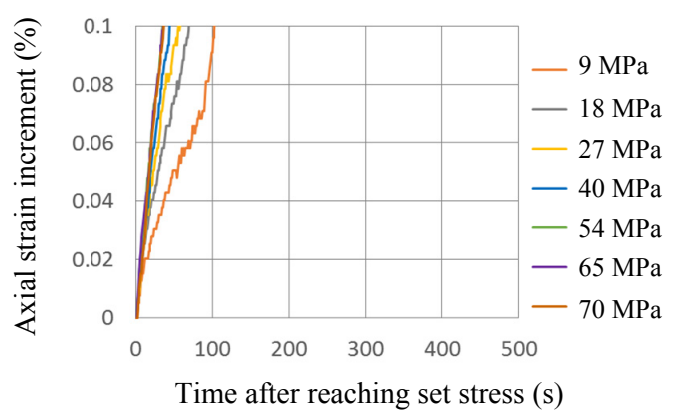

(b) Calcium hydroxide

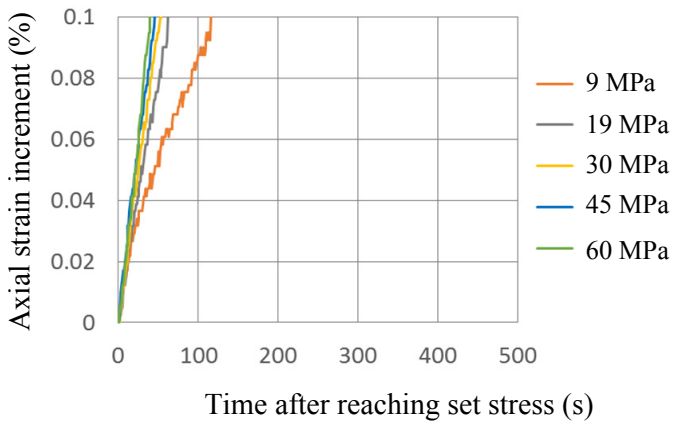

(d) Synthesised C-S-H
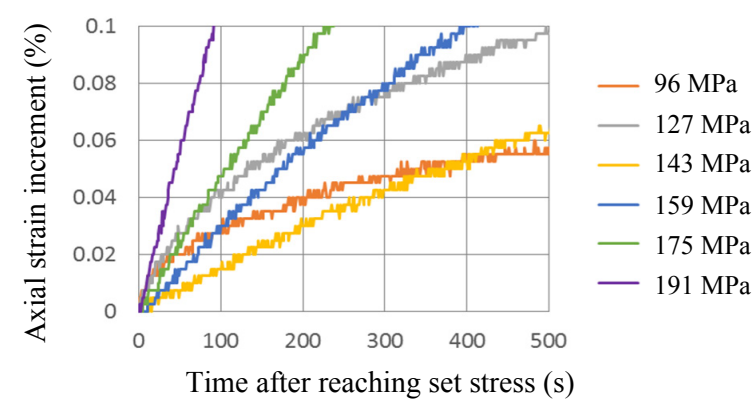

(e) Uncrushed cement paste

Fig. 9 Strain increment-time relationships of dry-compacted samples in stepwise creep test. (The set stress is shown in the right side of each figure) 
Only the cement paste exhibits a different behaviour: at low differential stress, the slope of the plots is almost zero, but later, it increases to one. The former three hydrates exhibit a large strain rate probably because they are not compacted well by dry compaction and the consolidation of the powder attributed to the measured strain rate. The crushed cement paste exhibits a small strain rate and different behaviour from the other hydrates probably because the particle size distribution is good, the strain development due to the consolidation is small, and the deformation of the particles is dominant.

Figure 12 shows the results of the wet compacted samples and the calculated strain rates are lower than that of dry compacted samples. In wet compaction, the compaction is accelerated by the water and the dissolved and precipitated hydrates can fill the gaps during drying after the compaction; therefore, the consolidation is not

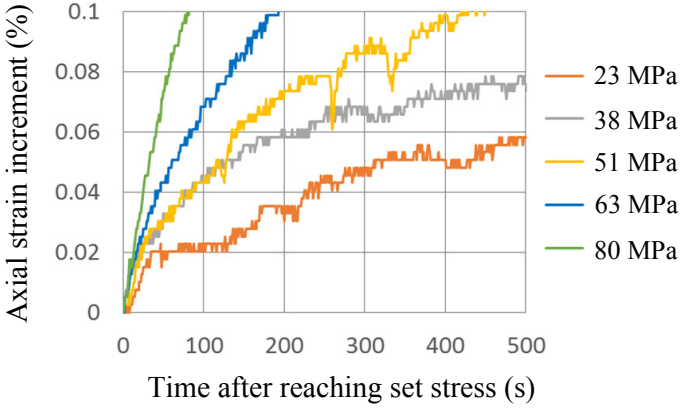

(a) Cement paste

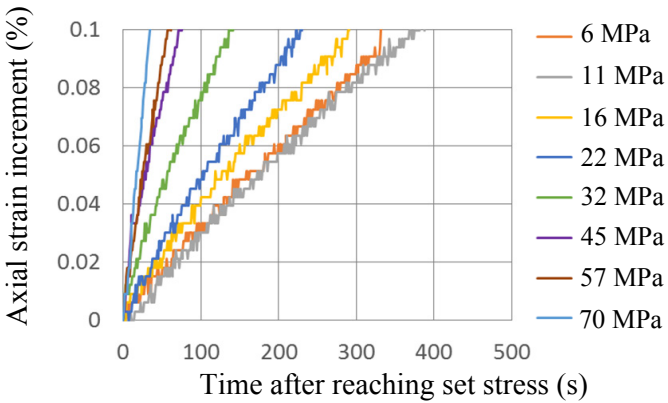

(c) Synthesised ettringite dominant in the creep test, but the deformation of the particles is. The strain rate of the uncrushed HCP is smaller than that of the crushed and compacted HCP at the same differential stress, and this difference is likely attributed to the difference in porosity. It is known that if HCPs have the same porosity, they exhibit similar mechanical properties even after crushing and compacting (Soroka and Sereda 1968).

As shown in Fig. 12, the cement paste and the hydrates exhibit similar trends at low stress: the slopes of the plots are small, but they increase to approximately three except for C-S-H. The plots of C-S-H are distributed irregularly: the slope of the plots is almost zero up to a differential stress of $30 \mathrm{MPa}$, but then, the strain rate suddenly increases and then gradually decreases. C-S-H deforms 10 times faster than calcium hydroxide and ettringite up to a differential stress of $20 \mathrm{MPa}$ and that the slope for C-S-H

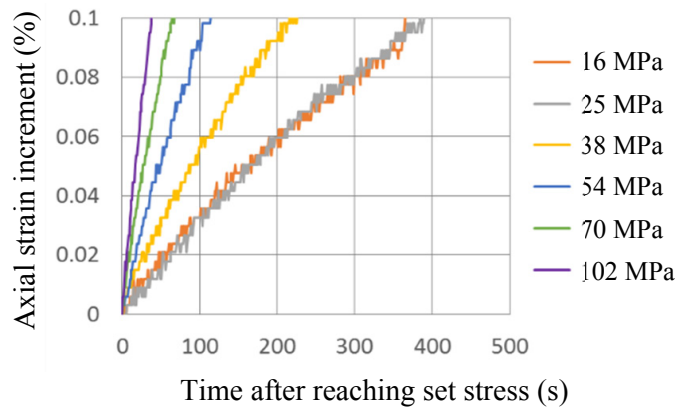

(b) Calcium hydroxide

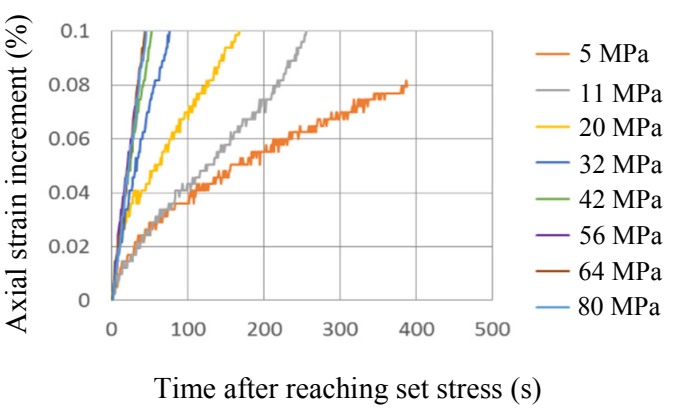

(d) Synthesised C-S-H

Fig. 10 Strain increment-time relationships of wet-compacted samples in stepwise creep test. (The set stress is shown in the right side of each figure)

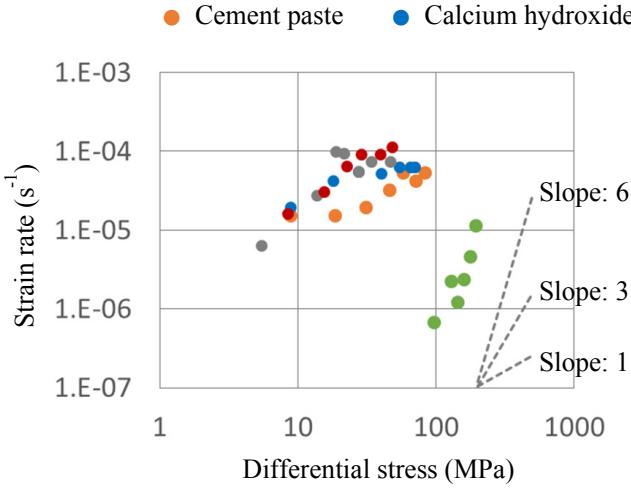

Fig. 11 Strain rate-differential stress relationship of dry-compacted samples in stepwise creep test.

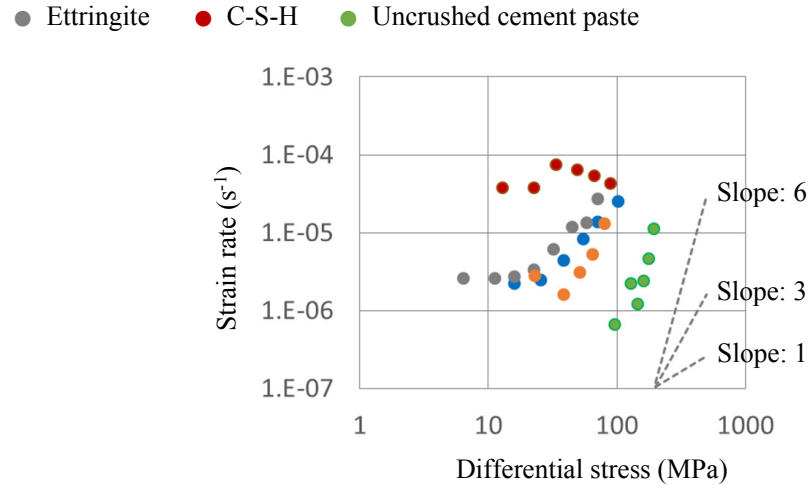

Fig. 12 Strain rate-differential stress relationship of wet-compacted samples in stepwise creep test. 
decreases as the stress increases, unlike the slopes for the other samples, which increase when the stress becomes larger than $20 \mathrm{MPa}$. This difference in the trend indicates that the synthesised C-S-H deforms faster than the other specimens and that the deformation of the synthesised $\mathrm{C}-\mathrm{S}-\mathrm{H}$ is governed by a different mechanism. The theory proposed by Sakai and Kishi (2017) has a contradiction: their results indicate that the deformation of HCP is governed by dislocation creep, but dislocation is generally defined only in a crystalline material. A large volume of HCP is composed of C-S-H, which is generally regarded to be a gel material. Therefore, dislocation cannot be defined in C-S-H. Our results resolve this contradiction: it is found that $\mathrm{C}-\mathrm{S}-\mathrm{H}$ deforms faster than the other hydrates (crystal hydrates) and probably C-S-H is squeezed out of the structural framework during the deformation. Figure 13 describes the process through which the crystal hydrates form a structure. C-S-H has the largest volume in HCP, and the other hydrates are scattered in HCP (Fig. 13(a)). As the applied stress increases, the deformation becomes larger, a larger amount of C-S-H is squeezed out, and the other hydrates form a structure (Fig. 13(b)). According to the percolation theory, a volume fraction of approximately $16 \%$ is necessary for the formation of a continuous cluster (Scher and Zallen 1970). The volume fraction of the hydrates other than C-S-H is $30-50 \%$, which is sufficiently large for the hydrates to form a cluster or structure. Then, these hydrates govern the deformation rate, and dislocation creep becomes the dominant deformation mechanism (Fig. 13(c)). Actually, with regard to the calcium hydroxide in concrete, it is observed that even the stress induced by drying shrinkage can initiate dislocation in calcium hy- droxide (Harutyunyan et al. 2003). Sakai et al. (2016) obtained the backscattered electron images of HCP after deformation and these images indicated a trace of flow; this trace may be attributed to the flow of C-S-H. In contrast, under low stress (e.g., 30\% of the compressive strength applied in a conventional creep test), the deformation of C-S-H takes time and is dominant (Fig. 14) until the other hydrates form a structure (Fig. 13(b)). In a conventional creep test of HCP, the final strain is not large $(0.1-0.3 \%)$ and the creep strain becomes almost constant (Morgan 1974; Parrott 1977; Tamtsia et al. 2004; Vu et al. 2012). This tendency indicates that $0.1-$ $0.3 \%$ strain is required before $\mathrm{C}-\mathrm{S}-\mathrm{H}$ is squeezed out; then, the other hydrates form a structure, and the increase in the creep strain is stagnated. In other words, before the strain reaches $0.1-0.3 \%$, the crystal hydrates do not form a structure, and the deformation of C-S-H governs the deformation of HCP.

Our results support this hypothesis: in Fig. 12, the slope of the plots of the compact made from crushed cement paste becomes three when the differential stress is larger than $30 \mathrm{MPa}$. In the results obtained by Sakai and Kishi (2017), for example, the uncrushed dry HCP tested at a confining pressure of $50 \mathrm{MPa}$ has a slope of six when the differential stress is larger than $70 \mathrm{MPa}$. These results indicate that for the structure formation by the hydrates other than $\mathrm{C}-\mathrm{S}-\mathrm{H}$, a deformation corresponding to approximately $0.1-0.3 \%$ strain is required, and the stress should be sufficiently high, several ten $\mathrm{MPa}$, to induce deformation in the formed structure. In a general creep test without confinement, the stress cannot increase up to this level because the specimen fails at a lower stress level. However, in concrete under high confining

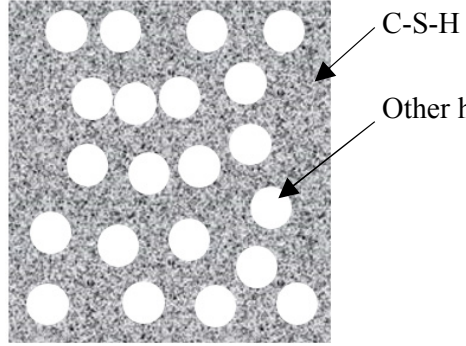

(a) Before deformation

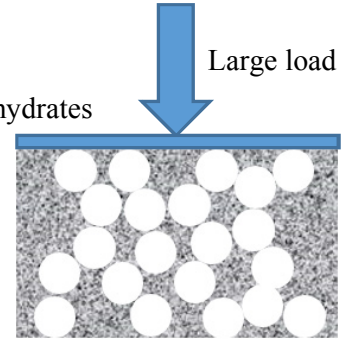

(b) Structure formed after large deformation

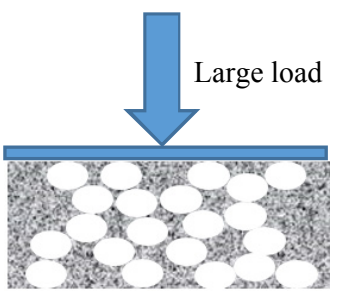

(c) Deformation of structure

Fig. 13 Schematic diagram of large deformation of HCP.

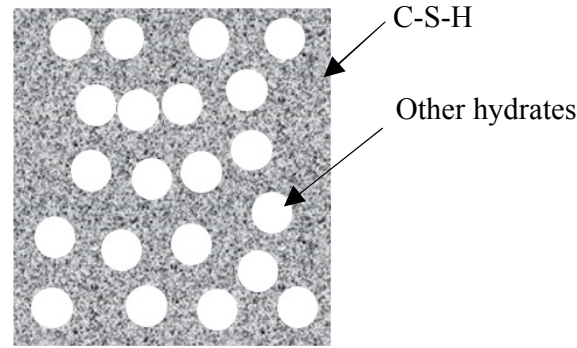

(a) Before deformation

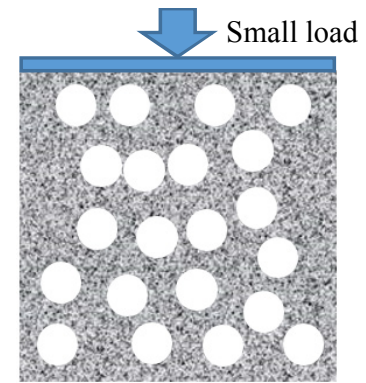

(b) After small deformation

Fig. 14 Schematic diagram of small deformation of HCP. 
pressure, such as a concrete structure deep under the sea or ground or a concrete structure surrounded by reinforcement, this stress level can be achieved. The formation and deformation of such a structure may not be apparent in a specimen without confinement because the specimen fails before the strain and stress become sufficiently high to form and deform such a structure. In this study, the stepwise creep test under the confining pressure suggested the formation of crystal hydrates and its deformation that is not observable without confinement. The findings of this study are expected to help us gain a better understanding of the deformation mechanism and the property of concrete. Further investigation is being conducted to obtain the evidences of dislocation in hydrates using a transmission electron microscope (TEM) etc.

\section{Conclusion}

In this study, to examine the deformation mechanism of cement paste, creep tests were performed on cement paste and synthesised hydrates. The normal creep test and the stepwise creep test showed similar trends; therefore, we concluded that the stepwise creep test is a valid method to obtain the relationship between the strain rate and the differential stress. The slope of this relationship indicated that the deformation of cement paste, calcium hydroxide, and synthesised ettringite is governed by dislocation creep. Only the synthesised C-S-H exhibited different behaviour from the other samples and faster deformation than the other samples. We proposed a concept that the deformation of C-S-H is dominant when the stress and strain of HCP are small, and as the stress increases, the other hydrates form a structure and the deformation of this structure become dominant.

\section{Acknowledgment}

This study was financially supported by Sekisui Chemical Co. Ltd.

\section{References}

Akçaoğlu, T., Tokyay, M. and Celik, T., (2004). "Effect of coarse aggregate size and matrix quality on ITZ and failure behavior of concrete under uniaxial compression." Cement and Concrete Composites, 26, 633-638.

Ali, I. and Kesler, C., (1964). "Mechanisms of creep in concrete." Proceedings of Symposium on Creep of Concrete, Detroit, 9, 35-63.

Brantut, N., Heap, M. J., Meredith, P. G. and Baud, P., (2016). "Time-dependent cracking and brittle creep in crustal rocks: A review." Journal of Structural Geology, 52, 17-43.

Bürgmann, R. and Dresen, G., (2008). "Rheology of the lower crust and upper mantle: Evidence from rock mechanics, geodesy, and field observations." Annual Review of Earth and Planetary Sciences, 36, 531-567.

Ferkel, H. and Mordike, B. L., (2001). "Magnesium strengthened by SiC nanoparticles." Materials Science and Engineering, A298, 193-199.

Gabet, T., Malecot, Y, and Daudeville, L., (2008). "Triaxial behaviour of concrete under high stresses: Influence of the loading path on compaction and limit states." Cement and Concrete Research, 38(3), 403-412.

Goldsby, D. L. and Kohlstedt, D. L., (1995). "The transition from dislocation to diffusion creep in ice." Abstracts of the Lunar and Planetary Science Conference, 26, 473.

Harutyunyan, V. S., Abovyan, E. S. and Monteiro, P. J. M., (2003). "X-ray diffraction investigations of deformations and dislocation configuration in calcium hydroxide crystallites of concrete." Physica Status Solidi, 200(2), 307-325.

Hsu, T. T. C., Slate, F. O., Sturman, G. M. and Winter, G., (1963). "Microcracking of plain concrete and the shape of the stress-strain curve." Proceedings of the American Concrete Institute, 60(2), 209-224.

Japan Cement Association, (2016). "Cement concrete chemistry." Japan Cement Association. (in Japanese)

Kainer, K. U., (2006). "Magnesium: Proceedings of the 6th International Conference Magnesium Alloys and Their Applications." Wiley.

Leo, R., (2017). "Probability Based High Temperature Engineering-Creep and Structural Fire Resistance-." Springer.

Malecot, Y., Daudeville, L., Dupray, F., Poinard, C. and Buzaud, E., (2010). "Strength and damage of concrete under high triaxial loading." European Journal of Environmental and Civil Engineering, 14(6-7), 777-803.

Mei, S. and Kohlstedt, D. L., (2000). "Influence of water on plastic deformation of olivine aggregates: 2 . Dislocation creep regime." Journal of Geophysical Research, 105(B9), 21471-21481.

Mihashi, H., Sasaki, T. and Izumi, M., (1979). "Failure process of concrete: Crack initiation and propagation." Proceedings of International Conference on Mechanical Behaviour of Materials, Cambridge, 97-107.

Morgan, D. R., (1974). "Possible mechanisms of influence of admixtures on drying shrinkage and creep in cement paste and concrete." Matériaux et Construction, 7(4), 283-289.

Nakamura, A., Sakai, E., Nishizawa, K., Ohba, Y. and Daimon, M., (1999). "Sorption of Chloride-ion, Sulfate-ion and Phosphate-ion in Calcium Silicate Hydrates." Journal of the Chemical Society of Japan, 6, 415-420.

Ngab, A. S., Nilson, A. H. and Slate, F. O., (1981). "Shrinkage and creep of high strength concrete." Journal of American Concrete Institute, 78(4), 255-261.

Okubo, S., Miyajima, T., Fujii, T., Onaka, S. and Kato, M., (2013). "Grain size variation during low temperature creep and tensile deformation of ultrafine-grained copper." Materials Transactions, 54(9), 1605-1611. 
Parrott, L. J., (1977). "Basic creep, drying creep and shrinkage of a mature cement paste after a heat cycle." Cement and Concrete Research, 7(5), 597-604.

Pickett, G., (1942). "The effect of change in moisture content on the creep of concrete under a sustained load." Proceedings of the American Concrete Institute, 38, 333-355.

Poinard, C., Malecot, Y. and Daudeville L., (2010). "Damage of concrete in a very high stress state: Experimental investigation." Materials and Structures, 43(1-2), 15-29.

Powers, T. C., (1968). "The thermodynamics of volume change and creep." Matériaux et Construction, 1(6), 487-507.

Rathbun, A. P., Marone, C., Alley, R. B. and Anandakrish-nan, S., (2008). "Laboratory study of the frictional rheology of sheared till." Journal of Geophysical Research, 113, F02020.

Rusch, H., (1961). "Researches toward a general flexural theory for structural concrete." Journal of American Concrete Institute, 57(1), 1-28.

Sakai, Y., Nakatani, M., Takeuchi, A., Omorai, Y. and Kishi, T., (2016). "Mechanical behavior of cement paste and alterations of hydrates under high-pressure triaxial testing." Journal of Advanced Concrete Technology, 14(1), 1-12.

Sakai, Y. and Kishi, T., (2017). "Deformation mechanism of hardened cement paste and effect of water." Journal of Advanced Concrete Technology, 15(1), 19-28.

Sato, E., Yamada, T., Tanaka, H. and Jimbo, I., (2005). "Categorization of ambient temperature creep behavior of metals and alloys on their crystallographic structures." Journal of Japan Institute of Light Metals, 55(11), 604-609.

Scher, H. and Zallen, R., (1970). "Critical density in percolation processes", The Journal of Chemical Physics, 53(9), 3759-3761.

Schuh, C. A., Hufnagel, T. C. and Ramamurty, U., (2007). "Mechanical behavior of amorphous alloys." Acta Materialia, 4067-4109.

Sfer, D., Carol, I., Gettu, R. and Etse, G., (2002). "Study of the behavior of concrete under triaxial compres- sion." Journal of Engineering Mechanics, 128(2), 156-163.

Shah, S. P. and Chandra, S., (1968). "Critical stress, volume change and microcracking of concrete." Proceedings of the American Concrete Institute, 65(9), 770-781.

Smadi, M. M., Slate, F. O. and Nilson, A. H., (1982). "Time-dependent behavior of high-strength concrete under high sustained compressive stresses." Research Report No. 82-16, Department of Structural Engineering, Cornell University.

Soroka, I. and Sereda, P. J., (1968). "The relation between hardness, modulus of elasticity and porosity in various systems of gypsum." Journal of the American Ceramic Society, 51(6), 337-40.

Sugino, Y., Ukai, S., Leng, B., Oono, N., Hayashi, S., Kaito, T. and Ohtsuka, S., (2012). "Grain boundary related deformation in ODS ferritic steel during creep test." Materials Transactions, 53(10), 1753-1757, Ithaca, NY.

Tamtsia, B. T., Beaudoin, J. J. and Marchand, J., (2004). "The Early age short-term creep of hardening cement paste: load-induced Hydration Effects." Cement and Concrete Composites, 26, 481-489.

Vu, M. H., Sulem, J. and Laudet, J. B., (2012). "Effect of the curing temperature on the creep of a hardened cement paste." Cement and Concrete Research, 42(9), 1233-1241.

Yamaguchi, E. and Chen, W. F., (1991). "Microcrack propagation study of concrete under compression." Journal of Engineering Mechanics, 117(3), 653-673.

Zhang, X. and Spiers, C. J., (2005). "Compaction of granular calcite by pressure solution at room temperature and effects of pore fluid chemistry." International Journal of Rock Mechanics and Mining Sciences, 42, 950-960.

Zheng, Z., McLennan, J. D. and Martin, J. W., (1991). "Compressive stress-induced microcracks and effective elastic properties of limestone and concrete." Final Technical Report to USAF, Topic No. AF90-186, Terra Tek Report TR91-107. 